\title{
Deprescribing: a primary care perspective
}

\author{
Polly Duncan, ${ }^{1}$ Martin Duerden, ${ }^{2}$ Rupert A Payne ${ }^{1}$
}

${ }^{1}$ Centre for Academic Primary Care, University of Bristol, Bristol, UK

${ }^{2}$ Centre for Health Economics and Medicines Evaluation, Bangor University, Bangor, UK

\section{Correspondence to}

Dr Rupert Payne, Centre for Academic Primary Care, University of Bristol, Office 1.01a, Canynge Hall, 39 Whatley Road, Bristol BS8 2PS, UK; r.payne@bristol.ac.uk

Received 19 April 2016 Revised 2 September 2016 Accepted 8 September 2016

EAHP Statement 6 Education and Research

\section{ABSTRACT}

Polypharmacy is an increasing and global issue affecting primary care. Although sometimes appropriate, polypharmacy can also be problematic, leading to a range of adverse consequences. Deprescribing is the process of supervised withdrawal of an inappropriate medication and has the potential to reduce some of the problems associated with polypharmacy. It is a complex and sensitive process. We examine the issue of deprescribing from the perspective of primary care. Key steps in the deprescribing process are a review of medications and corresponding indications, consideration of harms, assessment of eligibility for discontinuation, prioritisation of medications and implementation of a stopping plan with appropriate monitoring. Patient involvement is a key feature of this process. Deprescribing should be considered in the context of end-of-life care and medication safety, but approaches are also required to identify other situations where deprescribing is appropriate. General practitioners are well positioned to facilitate deprescribing, usually through formal medication review, with decisions informed by a range of other healthcare professionals. Guidelines are available that help guide these processes. A range of studies have explored attitudes towards deprescribing; patients are generally supportive of the concept, although clinician views are varied. The successful implementation of deprescribing strategies still requires important patient and clinician barriers to be overcome, and clinical trial evidence of effectiveness and safety is essential.

\section{INTRODUCTION}

Deprescribing has been defined as 'the process of withdrawal of an inappropriate medication, supervised by a health care professional with the goal of managing polypharmacy and improving outcomes'. ${ }^{1}$ This is particularly relevant to patients with polypharmacy (the prescription of multiple medications) because the risk of harm caused by medication increases with the number of medications a patient is prescribed. ${ }^{2}$ Stopping or reducing the dose of medications requires careful clinical consideration, with a need to balance issues such as potential loss of clinical benefit and increased patient anxiety, against reductions in medication errors, adverse reactions and prescribing burden. To reflect these complexities and sensitivities, the term 'deprescribing' has been adopted rather than simply stopping medicines. This requires similar levels of skill to prescribing in the first place.

This narrative review examines the issue of deprescribing from the perspective of primary care. In the UK, the general practitioner (GP) is the first point of contact with the health service for most patients, and gatekeeper to specialist services.
Virtually all UK residents are registered with a GP as part of the state-funded National Health Service, and the management of long-term conditions, including prescription of long-term medications, is mostly managed in this setting. We present personal expert opinion supported by a search of the academic literature based around the term 'deprescribing' and key policy documents.

The purpose of this review is to (i) describe trends in polypharmacy and explanations for why it is increasing; (ii) outline the harms associated with overtreatment; (iii) outline the rationale for deprescribing and different approaches to deprescribing within general practice, including the role of the pharmacist; (iv) outline the barriers and enablers to deprescribing; and (v) make recommendations for future practice.

\section{TRENDS IN POLYPHARMACY}

Polypharmacy is a global issue, affecting developed and developing nations (table 1). The prevalence of polypharmacy within the UK is increasing-in Scotland, the proportion of patients prescribed $\geq 5$ medications doubled to $20.8 \%$ from 1995 to 2010, and the proportion prescribed $\geq 10$ medications tripled to $5.8 \%$ over the same period (see table 1 ). ${ }^{3}$ A similar picture is seen in England, with national dispensing data showing a $64 \%$ increase in the number of medications dispensed in primary care from 2001 to $2011 .^{4}$ Importantly, most available data relate only to prescribed medications, and not over-the-counter or 'herbal' products, so medication use may be higher.

The rise in polypharmacy is being driven by numerous factors. One key factor is that our population is ageing, and this in turn is associated with increased multimorbidity (the coexistence of multiple long-term conditions in one individual). The number of people aged $\geq 85$ years is set to increase at the fastest rate, more than doubling to 3.6 million between 2014 and 2039. ${ }^{5}$ Multimorbidity has become the norm in UK general practice, with over half of adults having two or more long-term conditions and over three-quarters of general practice consultations involving patients with multimorbidity. ${ }^{6}$ Polypharmacy has been shown to have a clear association with both increasing age and number of long-term conditions, as well as female sex. $^{7-9}$ A further important factor is the trend to prescribe preventative medication to asymptomatic patients to prevent future disease and mortality. ${ }^{4}$ In the UK, this is partly due to a primary care payment-for-performance system (the Quality and Outcomes Framework) setting incentivised targets for GPs to treat common long-term conditions. The number of treatment guidelines has also increased in recent years, with most guidelines promoting commencement of new treatment and very
Duerden M, Payne RA. Eur J Hosp Pharm 2017:24:3742. 
Table 1 Selection of studies demonstrating international variation in prevalence of prescribed polypharmacy in community and primary care settings

\begin{tabular}{|c|c|c|c|c|c|c|}
\hline Study & Setting & Sample size & $\begin{array}{l}\text { Age of } \\
\text { participants }\end{array}$ & $\begin{array}{l}\text { Number of } \\
\text { medications }\end{array}$ & $\begin{array}{l}\text { Rates of } \\
\text { polypharmacy } \\
(\%)\end{array}$ & Notes \\
\hline Hovstadius et al ${ }^{9}$ & $\begin{array}{l}\text { Sweden, primary } \\
\text { care }\end{array}$ & 9219637 & $\begin{array}{l}\text { Total } \\
\text { population } \\
60-69 \text { years } \\
\geq 80 \text { years }\end{array}$ & $\begin{array}{l}\geq 5 \\
\geq 10 \\
\geq 5 \\
\geq 10 \\
\geq 5 \\
\geq 10\end{array}$ & $\begin{array}{r}11.1 \\
2.4 \\
21.4 \\
4.1 \\
52.3 \\
15.5\end{array}$ & Rates of polypharmacy increased with age. \\
\hline Qato et $a l^{72}$ & USA, community & 3005 & $57-85$ years & $\geq 5$ & 29 & $\begin{array}{l}\text { Rates of polypharmacy increased with age and } \\
\text { female gender. }\end{array}$ \\
\hline Dong et $a l^{73}$ & $\begin{array}{l}\text { Rural China, } \\
\text { primary } \\
\text { healthcare clinics }\end{array}$ & $\begin{array}{l}20125 \\
\text { prescriptions }\end{array}$ & $\begin{array}{l}\text { Total } \\
\text { population }\end{array}$ & $\geq 5$ & 5.8 & $\begin{array}{l}\text { Village doctor workload and government subsidies } \\
\text { influenced the rates of polypharmacy. Rates are per } \\
\text { prescription rather than per person. }\end{array}$ \\
\hline Richardson et $a l^{74}$ & $\begin{array}{l}\text { Ireland, } \\
\text { community }\end{array}$ & 8093 & $\geq 50$ years & $\begin{array}{l}\geq 5 \\
\geq 10\end{array}$ & $\begin{array}{r}19 \\
2\end{array}$ & $\begin{array}{l}\text { Rates of polypharmacy were greatest in those with } \\
\text { self-reported hypertension, hypercholesterolaemia, } \\
\text { arthritis, chronic pain and diabetes. }\end{array}$ \\
\hline Oliveira et $a l^{75}$ & $\begin{array}{l}\text { Brazil, primary } \\
\text { care }\end{array}$ & 142 & $\geq 60$ years & $\geq 4$ & 64.5 & Small study. \\
\hline Payne et $\mathrm{al}^{7}$ & $\begin{array}{l}\text { Scotland, primary } \\
\text { care }\end{array}$ & 180815 & $\begin{array}{l}\text { Total adult } \\
\text { population } \\
60-69 \text { years } \\
\geq 80 \text { years }\end{array}$ & $\begin{array}{l}4-9 \\
\geq 10 \\
4-9 \\
\geq 10 \\
4-9 \\
\geq 10\end{array}$ & $\begin{array}{r}16.9 \\
4.6 \\
28.6 \\
7.4 \\
51.8 \\
18.6\end{array}$ & $\begin{array}{l}\text { Polypharmacy increased with the number of } \\
\text { long-term conditions. }\end{array}$ \\
\hline
\end{tabular}

few promoting stopping medications. Importantly, the evidence base for many of these guidelines is derived from trials that often exclude elderly patients and patients with multimorbidity, ${ }^{10}$ and the recommendations seldom consider the cumulative impact of receiving treatment for more than one long-term condition or provide information about how to weigh up the risks and benefits of treatment. ${ }^{11} \mathrm{~A}$ further issue of particular relevance to UK general practice is the use of a system known as repeat prescribing, which enables patients to reorder long-term medications without requiring a further assessment by a clinician for long periods of time, and may contribute to polypharmacy. Although reviews of such prescriptions are usually undertaken at least annually, the effectiveness of these 'repeat' reviews in terms of rationalising treatment in the older, multimorbid population has been questioned. ${ }^{12}$

\section{HARMS OF POLYPHARMACY}

Before outlining the harms of overprescribing, it is important to distinguish problematic from appropriate polypharmacy. Appropriate polypharmacy describes the necessary use of multiple evidence-based medications to improve the quality of a person's life and extend their life. ${ }^{4}$ We have previously demonstrated that the adverse consequences of polypharmacy are dependent on clinical context and have cautioned against assumptions that polypharmacy is always harmful and represents poor care. ${ }^{13} 14$ There is also clear evidence, albeit not in the older, multimorbid population, for the benefits of some multiple medications, for example, in the context of cardiovascular risk reduction. ${ }^{15}$

Problematic polypharmacy describes the situation where the risk of taking multiple medications outweighs the benefit. ${ }^{4}$ There is strong evidence that increased numbers of medicines are associated with various adverse consequences, much of this evidence coming from primary care. This includes a greater risk of high-risk prescribing (ie, associated elevated risk of adverse drug events), ${ }^{16}$ medication errors, ${ }^{17}$ adverse drug reactions, ${ }^{18}$ poor adherence ${ }^{19}$ and impaired quality of life. ${ }^{20}$ This is particularly relevant in frail and older people, in whom pharmacokinetic and pharmacodynamic changes may increase vulnerability to, and magnitude of, medication side effects. ${ }^{21}$ Furthermore, these people may have cognitive impairment, visual impairment or loss of dexterity, making management of complex medication regimens more difficult and potentially more prone to error and hazard.

The burden of treatment-the effort of looking after one's health and the impact that this has on general well-being ${ }^{22}$-is also worth considering. Patients are responsible for coordinating their appointments, self-monitoring their conditions and finding ways to incorporate complex medical regimens into their everyday life. Taking a lot of drugs is a challenge for patients, particularly those from lower socioeconomic groups who may have lower numeracy and literacy levels. ${ }^{23}$ Patients with multimorbidity are often required to attend separate appointments for each of their long-term conditions and are at particular risk of high treatment burden. Mair and colleagues argue for 'minimally disruptive medicine', whereby individual preference, multimorbidity and treatment burden are at the centre of clinical decisions. $^{24}$

\section{RATIONALE FOR DEPRESCRIBING AND CURRENT APPROACHES}

Deprescribing is taken to mean more than simply stopping medicines and is considered to be a planned, stepwise process, specifying the type of medication in question, detailing explicit goals and including dose reduction and substitution. ${ }^{1}$ Deprescribing may have the potential to reduce pill burden, side effects, adverse drug events, medication errors, drug-drug interactions, and in doing so decrease health service use and morbidity, and improve quality of life and other health outcomes for patients. Interestingly, however, although the harms of inappropriate polypharmacy are reasonably well established, there is a lack of 
direct evidence for the benefits of deprescribing in the general practice setting.

\section{The deprescribing process}

Scott and colleagues have outlined five steps in the deprescribing process: first, find out what medications the patient is taking and the indications; second, consider the overall risk of drug-induced harm; third, assess each medication in terms of eligibility to be discontinued (eg, lack of indication, unacceptable treatment burden, harm outweighs benefit); fourth, prioritise which medications to stop; and finally, implement a plan to stop the medication and monitor the consequences. ${ }^{25}$ An earlier version of this model has been found to have face validity by hospital clinicians, ${ }^{26}$ but it is also highly likely to be appropriate to the general practice setting. A review by Reeve $e t a l^{27}$ found that, out of 10 published articles describing the deprescribing process or related elements, 4 included all five of these principles. The review also found evidence supporting the different principles, although this was limited in nature. For particular medications, such as selective serotonin reuptake inhibitors, there is a risk of discontinuation reactions. The final stage of the deprescribing process-planning how to stop the medication and arranging follow-up-is likely to reduce this risk.

The Royal Pharmaceutical Society ${ }^{28}$ outlines four guiding principles for medication optimisation (see figure 1)-referred to in the National Institute for Health and Care Excellence (NICE) Guidelines on Medicines Optimisation. ${ }^{2}$ These principles are understanding the patient's perspective, views and preferences; assessing the evidence base and cost-effectiveness of treatments; ensuring medicine safety; and establishing medication optimisation as part of routine practice. Although this model is not specifically focused on deprescribing, each of the principles is highly relevant to this process. In particular, patient involvement in decisions to change medications is a key feature.

A study in the south of England set out to explore the relationship between shared decision-making and patient satisfaction, adherence and perceived practitioner empathy. ${ }^{29}$ Prescribing decisions were common, occurring in $79 \%$ of consultations, but patients were given treatment options in only $21 \%$ of prescribing decisions and the patient's treatment preference was elicited in only $18 \%$ of decisions. Prescribing pharmacists were more likely to ask about patient preference than GPs and nurse prescribers. In consultations where more time was spent discussing treatment options, patient-reported satisfaction, adherence and practitioner empathy were rated more highly, although the issue of deprescribing was not specifically studied.

\section{Which patients?}

Deprescribing should be routinely considered in the context of preventative medication use in patients with reduced life expectancy, ${ }^{30}$ and particularly so in palliative cancer care. ${ }^{31}$ This is especially important given that $\geq 20 \%$ of palliative care patients are in receipt of inappropriate medications, ${ }^{31}$ and is very pertinent in the general practice setting, with GPs providing end-of-life care to $>40 \%$ of these patients. ${ }^{32}$ Increasingly it is recognised that people with non-cancer diseases such as severe chronic obstructive pulmonary disease and heart failure should also be assessed for stepping down treatment and end-of-life considerations. ${ }^{33}$ People in the care home setting are also likely to be at a point where deprescribing is indicated. Nevertheless, deprescribing is relevant in other clinical situations as well, particularly given that over a third of older general practice patients experience inappropriate prescribing. ${ }^{34}$ Objective measures of inappropriate prescribing (eg, Beers' criteria ${ }^{35}$ and the STOPP/

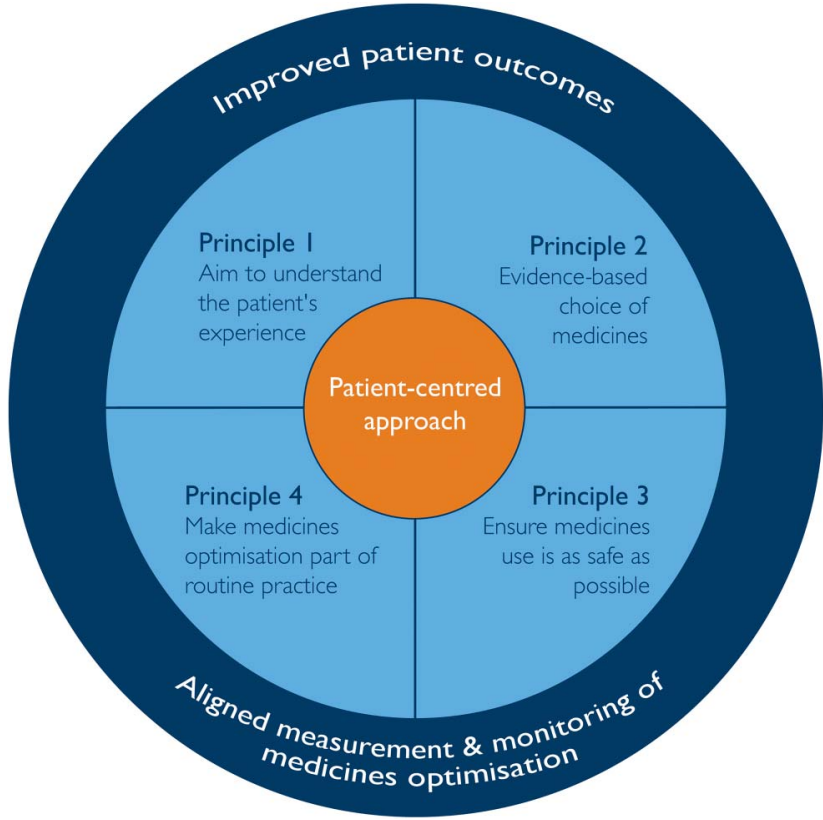

Figure 1 Summary of the four principles of medicines optimisation. ${ }^{28}$ Reproduced with permission from the Royal Pharmaceutical Society.

START criteria ${ }^{36}$ ) are a key primary care patient safety tool, ${ }^{37}$ and thus an important potential means of identifying individuals in whom deprescribing may be of value. A pragmatic approach of using a straightforward medication count potentially supplemented with indicators of problematic prescribing has been suggested in a King's Fund report. ${ }^{4}$ There is, however, a need for better approaches to identify situations where deprescribing is appropriate due to issues other than safety or end-of-life care.

\section{Which healthcare professional?}

The GPs are ideally positioned to facilitate deprescribing as they have access to the patient's full medical history (including current and drug history, diagnoses and investigations) to help inform medical decisions, and often an established relationship with the patient that imbues trust and supports shared decisionmaking. ${ }^{38}$ Decisions to reduce or stop medications are complex, particularly given that patients prescribed multiple medications often have a complex of long-term conditions. As such, GPs who achieve good continuity of care with their patients are perhaps best placed to make deprescribing decisions. Indeed, we have found evidence that there is an association between improved continuity of care and decreased total prescribing burden (Payne RA, unpublished data). In current practice, a formal medication review with a GP is likely to provide the best opportunity to enact decisions around deprescribing, with more dedicated time than is available during the opportunistic circumstances of other appointment types. There is no single agreed approach to the medication review process or the points that should be covered when considering stopping medicines. However, an example of some potential issues that might be considered is shown in box 1 . GPs seem readily able to add to medication, but stopping treatments is often not considered at the same time; maybe it would be best if all new medications were only commenced as a trial of therapy and substitution always considered as an alternative to addition. In a US study of primary care physician medication review, discontinuation of medicines was only reported by a fifth of patients. ${ }^{39}$ Evidence from hospital practice also suggests that recommendations to 
Box 1 Practical framework to guide stopping

medication $^{75}$

General advice

- Always regard starting a treatment as a trial.

- Always regard stopping a treatment as a trial.

- Unless there are significant adverse drug effects, there is usually plenty of time to stop or taper medicines one after another.

- Consider discussing with other clinicians and develop a clinical management plan to aid continuity.

Recognise the need to stop a medicine

- Any new problems or symptoms? Could these be related to adverse effects?

- Review the patient's and/or carer's concerns about the medicine.

- Consider the preferences of the patient (and/or carer).

- Is there still a clear clinical indication for the treatment (often this may be unclear or forgotten)?

- Has the clinical condition of the patient changed?

- Have the evidence or guidelines changed since a drug was initiated?

- If more than one medicine can be stopped, which one should be stopped first?

Reduce or stop one medicine at a time

- As much as possible reduce or stop one medicine at a time. If problems develop, it is then easier to know what the likely cause may be.

- Taper medicines when appropriate-examples where this may be particularly important include opioids, antidepressants, antipsychotics, $\beta$-blockers, hypnotics.

- Give patients (and/or carers) advice on any symptoms that might be expected when drugs are withdrawn. Often reassurance is all that is needed.

- If in doubt, taper, as it is safer.

- For many medicines, the first step in tapering is to halve the dose.

- Establish if the patient's symptoms, conditions or risks can be managed with a lower dose or whether the medicine can be stopped completely.

- Once tapering has begun, ask the patient to note any symptoms that may suggest a more gradual withdrawal is required.

Check for benefit or harm after each medicine has been stopped

- Ask the patient if any changes or problems have occurred after a medicine has been stopped.

- Beneficial effects may indicate that the decision to reduce or stop the medicine was correct.

- If symptoms of the initial condition return and are troublesome, despite gradual tapering, then it may be that the medicine cannot be stopped completely.

stop medications are not acted upon, ${ }^{40}$ and evidence from a community-based older population found that a quarter of medications that had been stopped were reintroduced within the following 12 months. ${ }^{41}$

GP deprescribing decisions can also be informed by a range of other healthcare professionals, who may have more time than the GP to dedicate to a prescribing review. Primary care nurses often have a central role in managing common long-term conditions in general practice, and Brandt has discussed nurse-led approaches to deprescribing, which are highly relevant to general practice. ${ }^{42}$ Community pharmacists also have a valuable role with respect to deprescribing. One particular intervention type is medication use reviews (MURs), structured adherencecentred reviews particularly focused on long-term conditions in patients subject to polypharmacy. There is evidence that clinical pharmacist medication reviews can reduce numbers of prescribed drugs, ${ }^{43}$ and the PINCER trial showed that a pharmacist-led intervention in general practice could reduce hazardous prescribing. ${ }^{44}$ However, the specific evidence for MURs by community pharmacists is limited. ${ }^{45}$ There has been a recent call to increase the role of clinical or practice pharmacists to work directly in general practice to address unmet workforce demands, ${ }^{46}$ and pilot work is being undertaken to explore this in England. ${ }^{47}$ Finally, although the continuing provision of medication for long-term problems is usually managed by the GP, hospital clinicians (in particular clinical pharmacists and generalist physicians such as geriatricians) can contribute to deprescribing, and hospital-based interventions to identify and stop unnecessary medication for elderly inpatients have indeed been found to be effective. ${ }^{48}$ Importantly, given that a single patient's management may involve multiple professionals from several healthcare settings, it is essential that the deprescribing process is coordinated and supported by good communication and cooperation.

\section{Guidelines}

In the UK, clinical guidance has been published by both Wales and Scotland, detailing approaches to polypharmacy of which medication review is considered central. ${ }^{49}{ }^{50}$ Both of these identify a number of important clinical areas to focus on, chosen largely on the basis of expert opinion; trial evidence for the effectiveness of the proposed approaches is lacking however. Other priorities have been set by survey work and expert panel opinion undertaken by Farrell and colleagues, which found key classes of medications to include benzodiazepines, atypical antipsychotics, statins, tricyclic antidepressants and proton pump inhibitors (PPIs); ${ }^{51}$ three of these areas are the focus of ongoing work developing evidence-based guidance for deprescribing in these specific therapeutics areas. Lindsay $e a^{52}$ have also developed and validated a deprescribing guideline specifically for palliative cancer patients.

Treating the patient as central to the medication optimisation process is a key principle outlined by NICE. ${ }^{2}$ Conklin and colleagues have published a protocol for a study to investigate improving implementation of deprescribing guidelines. ${ }^{53}$

\section{Trial evidence}

Despite the existence of systems that theoretically support deprescribing as well as the development of clinical guidance, trial evidence for deprescribing processes and improved outcome is relatively lacking. An Australian feasibility study by Reeve et $a l,{ }^{54}$ based on the five-step process outlined above, tested a patient-centred intervention to deprescribe PPIs for adults with polypharmacy. The study found that the process was acceptable and could reduce inappropriate PPI use in a small proportion of patients, but there were important barriers to implementation. A Canadian trial of a patient education intervention targeted at patients through community pharmacies demonstrated effectiveness at reducing benzodiazepine use in older adults. ${ }^{55} \mathrm{~A}$ systematic review of medication withdrawal found four trials supporting the safe reduction of diuretic therapy (albeit not in heart failure) and some improvements following reduction in psychotropic medication. ${ }^{56}$ Antipsychotic 
withdrawal has also been found to be safe in the majority of people with dementia. ${ }^{57}$ Despite hypertension being the most prevalent long-term condition in older people, randomised trials of antihypertensive withdrawal are lacking, although prospective observational studies suggest many patients remain normotensive. ${ }^{56}$

\section{BARRIERS AND FACILITATORS TO DEPRESCRIBING}

A range of studies have explored patients', carers' and clinicians' attitudes towards deprescribing.

\section{Patient and carer views}

Certainly, overall, patients are supportive of the idea of deprescribing. The term deprescribing may not be acceptable to some patients, however, who might associate it with money saving. ${ }^{58} \mathrm{~A}$ survey of Australian care homes found $40 \%$ of residents expressed a wish to reduce their medications with over threequarters willing to do so if deemed possible by their doctor. ${ }^{59}$ Patients taking nine or more medications were more likely to report medication side effects but no more likely to want to reduce their medications compared with those taking fewer medications. A further survey of older ambulatory care adults using the same scale-the 'Patient's Attitudes to Deprescribing Questionnaire'-found that $>90 \%$ were willing to stop one or more medications. ${ }^{38}$ Again willingness to stop medications was not found to be associated with the number of regular medications prescribed; however, the study was inadequately powered with only 100 study participants. A systematic review found that patient-reported barriers to deprescribing included disagreement over the appropriateness of stopping medication (eg, views that the medication was necessary to prevent future illness); lack of a process to stop medication (eg, the GP lacking time or knowledge to safely stop medication) and fear of stopping medications (eg, fear of withdrawal effects, fear of a medical condition returning or previous negative experiences of stopping medications). ${ }^{60}$ Enablers to deprescribing were agreement that it was appropriate to stop the medication, a system to stop or taper down the medication and a dislike of taking medications (eg, the inconvenience of having to take complex medication regimens and concerns that medications were 'unnatural').

\section{Clinician views}

Anderson $e t a l^{61}$ conducted a systematic review and thematic synthesis of qualitative studies that explored prescribers' perceived barriers and enablers to minimising potentially inappropriate medications for adults with long-term conditions. Twenty-one studies were included, and most focused on the views of primary healthcare physicians towards managing elderly patients. Factors that influenced decisions of whether or not to deprescribe were grouped as being intrinsic to the prescriber (eg, their beliefs, attitudes, knowledge, skills and behaviour) or extrinsic to the prescriber (eg, the patient, work setting, health system and cultural factors). Clinician inertia, whereby the clinician is aware of the potential harmful effects of medications but chooses not to act on this knowledge and stop the medication, was key. Reasons for this included not wanting to generate more work (eg, having to monitor the effects of stopping medications or overcoming logistical issues such as making changes to dosette boxes); avoiding conflict with other healthcare professionals who may have started the medication; concerns about a relapse of symptoms; and beliefs that, by continuing the medications, the patient was unlikely to come to harm.

A substudy of the ECSTATIC trial investigated attitudes to stopping preventive cardiovascular medication. ${ }^{62}$ GPs reported that their decision to stop unnecessary medication was influenced by their perception that specialists would disapprove of them stopping medications. A study in New Zealand investigated GPs' views on deprescribing in multimorbid elderly patients. ${ }^{63}$ Considerable variation in opinions on deprescribing was observed between GPs, and the authors proposed better guidelines for stopping medicines in order to reduce such variation.

A survey of physicians specialising in care of the elderly attitudes to deprescribing found that limited life expectancy, cognitive impairment and pill burden were important drivers to deprescribing. ${ }^{64}$

In a recent South Australian study, GPs ranked evidence for deprescribing and patient/family communication as the most important factors to consider when considering stopping medications. This differed from other healthcare professionals, with nurses prioritising doctors' receptivity to deprescribing and patient advocacy, and pharmacists prioritising clinical appropriateness and identifying patients' goals. ${ }^{65}$

\section{Special groups: care home residents, palliative care patients and the very elderly}

There are a number of groups for whom deprescribing may be particularly relevant. Tailored approaches to managing the process specific to these groups may need to be considered.

A study in Australia sought to explore the views of care home residents, relatives and care professionals towards polypharmacy and deprescribing. ${ }^{66}$ Care home residents reported that taking lots of medication was burdensome but they lacked understanding of what the medications were for and of potential harms caused by the medication. They trusted their GP and were willing to accept changes, including stopping medications, if they were suggested by their GP. Barriers to deprescribing reported by GPs included a lack of time, poor medical record keeping for care home residents, limited training of care home workers and difficulties with collaborating with care home workers and pharmacists.

A qualitative study in the USA to explore palliative care patients', carers' and healthcare professionals' views on stopping unnecessary medications, such as statins, found that patients were accepting of the concept of stopping preventative medications once they had come to terms with the fact that their illness was life-limiting. ${ }^{67}$ The authors concluded that it was important to explore patients' expectations of their illness and treatment, and to time discussions about stopping medications appropriately.

A study of Dutch GPs' views on deprescribing in the very elderly found that GPs broadly categorised medications into 'symptomatic medication' and 'preventative medication' ${ }^{68}$ Deciding to deprescribe preventative medication was seen as more difficult for GPs because there was a lack of guidance about the risk/benefit ratio. GPs believed that patients did not have a problem taking multiple medications and were worried that by stopping medication patients would feel that they were giving up on them. They were reluctant to discuss issues about approaching the end of life with patients. Other barriers to deprescribing included having to comply with guidelines to increase medications.

\section{RECOMMENDATIONS FOR THE FUTURE}

Guthrie et $a l^{69}$ make several suggestions of how guidelines could better inform treatment of people with multimorbidity. The first is to increase the number of cross-referenced guidelines. The paper cites an existing NICE guideline that provides advice on choice of antidepressant medication depending on 
coexistence of physical long-term conditions and co-prescribing. A second recommendation is for existing quick reference guidelines to contain more information about the magnitude of the likely benefit, some information about the potential harm of medication and an idea of how long the patient needs to take the medication to benefit from it. A final suggestion is to improve the evidence base by including elderly patients with multimorbidity in clinical trials.

Although there is good evidence that polypharmacy can be harmful to patients, there is a lack of evidence for the benefit from, or safety of, reducing or stopping medications, particularly within a primary care setting. Trial evidence for deprescribing is poor. Further research is needed to determine whether reducing or stopping potentially inappropriate medications, such as antihypertensive medication and PPIs, maintains or improves health outcomes for patients. There is some evidence that interventions to improve appropriate prescribing of medication reduce pill burden, but studies have been inadequately powered to investigate clinical outcomes, such as health-related quality of life and health service use.

In the UK, NICE has recently published a guideline on multimorbidity, which acknowledges the need to stop medicines as part of developing an individualised management plan for people with multimorbidity. ${ }^{70}$ An accompanying database comparing risks and benefits of treatments for common long-term medications has also been developed. The Canadian Deprescribing Network has developed an online tool providing guidance on tapering a range of medications. ${ }^{71}$ Such tools and guidance may be of value in empowering GPs to deprescribe, but effective implementation will be essential.

\section{CONCLUSION}

Polypharmacy is a major challenge for modern healthcare systems, driven by ageing, increasingly multimorbid populations and with growing adherence to protocol-driven practice and the use of evidence-based guidelines that focus on single diseases. Safe approaches for dealing with problematic polypharmacy are essential with medication reviews being an important component; deprescribing is one approach to rationalisation of medicines to minimise risk and achieve better outcomes. GPs and pharmacists are ideally placed to carry this out; the role of the latter should be developed further. Guidance to support prescribers in the reduction of medications is becoming more readily accessible, which follow a number of well-described principles and ensure that patient involvement with shared decision-making is central to the process. However, clinical trial evidence of clinical effectiveness and safety, as well as cost-effectiveness, is still required, and there remain numerous patient and clinician barriers to the successful implementation of deprescribing strategies.

Contributors RP and PD researched and wrote the article. MD added to the article and made revisions where appropriate.

Competing interests None declared.

Provenance and peer review Not commissioned; externally peer reviewed.

\section{REFERENCES}

1 Reeve E, Gnjidic D, Long J, et al. A systematic review of the emerging definition of 'deprescribing' with network analysis: implications for future research and clinical practice. Br J Clin Pharmacol 2015;80:1254-68.

2 Medication optimisation: the safe and effective use of medicines to enable the best possible outcomes. 2015. https://www.nice.org.uk/guidance/ng5 (last accessed 15 Aug 2016).

3 Guthrie B, Makubate B, Hernandez-Santiago V, et al. The rising tide of polypharmacy and drug-drug interactions: population database analysis 19952010. BMC Med 2015;13:74.
4 Duerden M, Avery T, Payne R. Polypharmacy and medicines optimisation: making it safe and sound. London: The King's Fund, 2013.

5 Office for National Statistics, London, National Population Projections: 2014-based Statistical Bulletin. October 2015. https://www.ons.gov.uk/ peoplepopulationandcommunity/populationandmigration/populationprojections/ bulletins/nationalpopulationprojections/2015-10-29.

6 Salisbury C, Johnson L, Purdy S, et al. Epidemiology and impact of multimorbidity in primary care: a retrospective cohort study. Br I Gen Pract 2011;61:e12-21.

7 Payne RA, Avery AJ, Duerden M, et al. Prevalence of polypharmacy in a Scottish primary care population. Eur J Clin Pharmacol 2014;70:575-81.

8 Hovstadius B, Astrand B, Petersson G. Assessment of regional variation in polypharmacy. Pharmacoepidemiol Drug Saf 2010;19:375-83.

9 Hovstadius B, Hovstadius K, Astrand B, et al. Increasing polypharmacy —an individualbased study of the Swedish population 2005-2008. BMC Clin Pharmacol 2010;10:16.

10 Van Spall HG, Toren A, Kiss A, et al. Eligibility criteria of randomized controlled trials published in high-impact general medical journals: a systematic sampling review. JAMA 2007;297:1233-40.

11 Hughes LD, McMurdo ME, Guthrie B. Guidelines for people not for diseases: the challenges of applying UK clinical guidelines to people with multimorbidity. Age Ageing 2013;42:62-9.

12 Oliver D. Care and quality indicators: QOF and public health priorities don't improve care in ageing. BMJ 2008;337:a1403.

13 Appleton SC, Abel GA, Payne RA. Cardiovascular polypharmacy is not associated with unplanned hospitalisation: evidence from a retrospective cohort study. BMC Fam Pract 2014;15:58.

14 Payne RA, Abel GA, Avery AJ, et al. Is polypharmacy always hazardous? A retrospective cohort analysis using linked electronic health records from primary and secondary care. Br J Clin Pharmacol 2014;77:1073-82.

15 Yusuf S, Pais P, Afzal R, et al. Effects of a polypill (Polycap) on risk factors in middle-aged individuals without cardiovascular disease (TIPS): a phase II, double-blind, randomised trial. Lancet 2009;373:1341-51.

16 Guthrie B, McCowan C, Davey P, et al. High risk prescribing in primary care patients particularly vulnerable to adverse drug events: cross sectional population database analysis in Scottish general practice. BMJ 2011;342:12.

17 Avery T, Barber N, Ghaleb M, et al. Investigating the prevalence and causes of prescribing errors in general practice: The PRACtICe Study(PRevalence AND Causes of prescrlbing errors in general practiCe), 2012. http://www.gmcuk.org/lnvestigating_the prevalence_and_causes_of_prescribing_errors_in_general_practice__The_PRACtICe_ study_Reoprt_May_2012_48605085.pdf (last accessed 15 Aug 2016).

18 Dequito $A B, M o l$ PG, van Doormaal JE, et al. Preventable and non-preventable adverse drug events in hospitalized patients: a prospective chart review in the Netherlands. Drug Saf 2011;34:1089-100.

19 Vik SA, Maxwell CJ, Hogan DB. Measurement, correlates, and health outcomes of medication adherence among seniors. Ann Pharmacother 2004;38:303-12.

20 Fincke BG, Miller DR, Spiro A. The interaction of patient perception of overmedication with drug compliance and side effects. I Gen Intern Med 1998;13:182-5.

21 Mangoni AA, Jackson SH. Age-related changes in pharmacokinetics and pharmacodynamics: basic principles and practical applications. Br I Clin Pharmacol 2004; $57: 6-14$

22 Eton DT, Ramalho de Oliveira D, Egginton JS, et al. Building a measurement framework of burden of treatment in complex patients with chronic conditions: a qualitative study. Patient Relat Outcome Meas 2012;3:39-49.

23 Mair FS, May CR. Thinking about the burden of treatment. BMJ 2014;349:g6680.

24 May C, Montori VM, Mair FS. We need minimally disruptive medicine. BMJ 2009;339:b2803.

25 Scott IA, Hilmer SN, Reeve E, et al. Reducing inappropriate polypharmacy: the process of deprescribing. JAMA Intern Med 2015;175:827-34.

26 Scott IA, Gray LC, Martin JH, et al. Effects of a drug minimization guide on prescribing intentions in elderly persons with polypharmacy. Drugs Aging 2012;29:659-67.

27 Reeve E, Shakib S, Hendrix I, et al. Review of deprescribing processes and development of an evidence-based, patient-centred deprescribing process. Br $\mathrm{Cl}$ Clin Pharmacol 2014;78:738-47.

28 Royal Pharmaceutical Society. Medicines Optimisation. Helping patients to make the most of medicines. 2013. https://www.rpharms.com/promoting-pharmacy-pdfs/ helping-patients-make-the-most-of-their-medicines.pdf (last accessed 15 Aug 2016).

29 Weiss MC, Platt J, Riley R, et al. Medication decision making and patient outcomes in GP, nurse and pharmacist prescriber consultations. Prim Health Care Res Dev 2015;16:513-27.

30 Todd A, Holmes HM. Recommendations to support deprescribing medications late in life. Int I Clin Pharm 2015;37:678-81.

31 Lindsay J, Dooley M, Martin J, et al. Reducing potentially inappropriate medications in palliative cancer patients: evidence to support deprescribing approaches. Support Care Cancer 2014;22:1113-19.

32 Office for National Statistics. Place of death statistics. UK Statistics Authority. 2013. http://www.endoflifecare-intelligence.org.uk/data_sources/place_of_death (last accessed 15 Aug 2016). 
33 Burge $F$, Lawson B, Mitchell G. How to move to a palliative approach to care for people with multimorbidity. BMJ 2012;345:e6324.

34 Moriarty F, Hardy C, Bennett K, et al. Trends and interaction of polypharmacy and potentially inappropriate prescribing in primary care over 15 years in Ireland: a repeated cross-sectional study. BMJ Open 2015;5:e008656.

35 By the American Geriatrics Society 2015 Beers Criteria Update Expert Panel. American Geriatrics Society 2015 Updated Beers Criteria for Potentially Inappropriate Medication Use in Older Adults. J Am Geriatr Soc 2015;63: 2227-46.

36 O'Mahony D, O'Sullivan D, Byrne S, et al. STOPP/START criteria for potentially inappropriate prescribing in older people: version 2. Age Ageing 2015;44:213-18.

37 Spencer $R$, Campbell SM. Tools for primary care patient safety: a narrative review. BMC Fam Pract 2014;15:166.

38 Reeve E, Wiese MD, Hendrix I, et al. People's attitudes, beliefs, and experiences regarding polypharmacy and willingness to Deprescribe. J Am Geriatr Soc 2013;61:1508-14.

39 Fillit HM, Futterman R, Orland Bl, et al. Polypharmacy management in Medicare managed care: changes in prescribing by primary care physicians resulting from a program promoting medication reviews. Am J Manag Care 1999;5:587-94.

40 Kroenke K, Pinholt EM. Reducing polypharmacy in the elderly. A controlled trial of physician feedback. J Am Geriatr Soc 1990;38:31-6.

41 Lampela $\mathrm{P}$, Hartikainen $\mathrm{S}$, Lavikainen $\mathrm{P}$, et al. Effects of medication assessment as part of a comprehensive geriatric assessment on drug use over a 1-year period: a population-based intervention study. Drugs Aging 2010;27:507-21.

42 Brandt NJ. Optimizing medication use through deprescribing: tactics for this approach. J Gerontol Nurs 2016;42:10-14.

43 Holland R, Desborough J, Goodyer L, et al. Does pharmacist-led medication review help to reduce hospital admissions and deaths in older people? A systematic review and meta-analysis. Br J Clin Pharmacol 2008;65:303-16.

44 Avery AJ, Rodgers S, Cantrill JA, et al. A pharmacist-led information technology intervention for medication errors (PINCER): a multicentre, cluster randomised, controlled trial and cost-effectiveness analysis. Lancet 2012;379:1310-19.

45 Anne H. Medicines use review by community pharmacists. Public Health Wales, 2011. https://www2.nphs.wales.nhs.uk/PharmaceuticalPHTDocs.nsf/ (last accessed 15 Aug 2016)

46 Roland PM. The future of primary care: creating teams for tomorrow, Report by the primary care workforce commission. 2015. https://www.hee.nhs.uk/sites/default/ files/documents/WES_The-future-of-primary-care.pdf (last accessed 15 Aug 2016).

47 Snow-Miller R. Clinical Pharmacists in General Practice Pilot: NHS England and Health Education England. July 2015. https://www.england.nhs.uk/commissioning/ primary-care-comm/gp-action-plan/cp-gp-pilot/ (last accessed 15 Aug 2016).

48 McKean M, Pillans P, Scott IA. A medication review and deprescribing method for hospitalised older patients receiving multiple medications. Intern Med J 2016:46:35-42.

49 Polypharmacy: Guidance for Prescribing. All Wales Medicines Strategy Group. July 2014. http://www.awmsg.org/docs/awmsg/medman/ (last accessed 15 Aug 2016).

50 Polypharmacy Guidance (second edition). In: Group. SGMoCPW, ed. 2015. http:/l www.sign.ac.uk/pdf/polypharmacy guidance.pdf (last accessed 15 Aug 2016).

51 Farrell B, Tsang C, Raman-Wilms L, et al. What are priorities for deprescribing for elderly patients? Capturing the voice of practitioners: a modified delphi process. PLOS ONE 2015;10:e0122246.

52 Lindsay J, Dooley M, Martin J, et al. The development and evaluation of an oncological palliative care deprescribing guideline: the 'OncPal deprescribing guideline'. Support Care Cancer 2015;23:71-8.

53 Conklin J, Farrell B, Ward N, et al. Developmental evaluation as a strategy to enhance the uptake and use of deprescribing guidelines: protocol for a multiple case study. Implement Sci 2015;10:91.

54 Reeve E, Andrews JM, Wiese MD, et al. Feasibility of a patient-centered deprescribing process to reduce inappropriate use of proton pump inhibitors. Ann Pharmacother 2015;49:29-38.
55 Tannenbaum C, Martin P, Tamblyn R, et al. Reduction of inappropriate benzodiazepine prescriptions among older adults through direct patient education: the EMPOWER cluster randomized trial. JAMA Intern Med 2014;174:890-8.

56 Iyer S, Naganathan V, McLachlan AJ, et al. Medication withdrawal trials in people aged 65 years and older: a systematic review. Drugs Aging 2008;25:1021-31.

57 Declerca T, Petrovic M, Azermai M, et al. Withdrawal versus continuation of chronic antipsychotic drugs for behavioural and psychological symptoms in older people with dementia. Cochrane Database Syst Rev 2013;(3):CD007726.

58 Cahill L. Polypharmacy and deprescribing: a special report on views from the PrescQIPP landscape review. PrescQIPP Strategic Oversight Group, 2014.

59 Kalogianis MJ, Wimmer BC, Turner JP, et al. Are residents of aged care facilities willing to have their medications deprescribed? Res Social Adm Pharm 2016:12:784-8

60 Reeve E, To J, Hendrix I, et al. Patient barriers to and enablers of deprescribing: a systematic review. Drugs Aging 2013;30:793-807.

61 Anderson $K$, Stowasser D, Freeman C, et al. Prescriber barriers and enablers to minimising potentially inappropriate medications in adults: a systematic review and thematic synthesis. BMJ Open 2014;4:e006544.

62 Luymes $\mathrm{CH}$, van der Kleij RM, Poortvliet RK, et al. Deprescribing potentially inappropriate preventive cardiovascular medication: barriers and enablers for patients and general practitioners. Ann Pharmacother 2016;50:446-54.

63 Ailabouni NJ, Nishtala PS, Mangin D, et al. General practitioners' insight into deprescribing for the multimorbid older individual: a qualitative study. Int I Clin Pract 2016;70:261-76.

64 Ní Chróinín D, Ní Chróinín C, Beveridge A. Factors influencing deprescribing habits among geriatricians. Age Ageing 2015;44:704-8.

65 Turner JP, Edwards S, Stanners M, et al. What factors are important for deprescribing in Australian long-term care facilities? Perspectives of residents and health professionals. BMJ Open 2016;6:e009781.

66 Palagyi A, Keay L, Harper J, et al. Barricades and brickwalls—a qualitative study exploring perceptions of medication use and deprescribing in long-term care. BMC Geriatr 2016;16:15.

67 Todd A, Holmes H, Pearson S, et al. 'I don't think I'd be frightened if the statins went': a phenomenological qualitative study exploring medicines use in palliative care patients, carers and healthcare professionals. BMC Palliat Care 2016;15:13.

68 Schuling J, Gebben $\mathrm{H}$, Veehof $\mathrm{L}$, et al. Deprescribing medication in very elderly patients with multimorbidity: the view of Dutch GPs. A qualitative study. BMC Fam Pract 2012;13:56.

69 Guthrie B, Payne K, Alderson P, et al. Adapting clinical guidelines to take account of multimorbidity. BMJ 2012;345:e6341.

70 Multimorbidity: clinical assessment and management. NICE guideline: (NG56). 2016. https://www.nice.org.uk/guidance/NG56

71 The Canadian Deprescribing Network. Medstopper, a deprescribing resource for health professionals and their patients. http://medstopper.com/ (last accessed 15 Aug 2016).

72 Qato DM, Alexander GC, Conti RM, et al. Use of prescription and over-the-counter medications and dietary supplements among older adults in the United States. JAMA 2008:300:2867-78.

73 Dong L, Yan H, Wang D. Polypharmacy and its correlates in village health clinics across 10 provinces of Western China. J Epidemiol Community Health 2010;64:549-53.

74 Richardson K, Moore P, Pekar J, et al. Polypharmacy in adults over 50 in Ireland: Opportunities for cost saving and improved healthcare. The Irish Longitudinal Study on Ageing. December 2012. http://tilda.tcd.ie/assets/pdf/PolypharmacyReport.pdf (last accessed 15 Aug 2016).

75 Oliveira MG, Amorim WW, de Jesus SR, et al. Factors associated with potentially inappropriate medication use by the elderly in the Brazilian primary care setting. Int J Clin Pharm 2012;34:626-32.

76 Duerden $M$, Payne R. Medicines management: the importance of when to stop. Prescriber 2015:24-6. 